\title{
Identity Uncertainty and Commitment Making Across Adolescence: Five-Year Within-Person Associations Using Daily Identity Reports
}

\author{
Andrik I. Becht, Stefanie A. Nelemans, \\ Susan J. T. Branje, and Wilma A. M. Vollebergh \\ Utrecht University
}

\author{
Hans M. Koot \\ VU University Amsterdam and EMGO Institute for Health and \\ Care Research
}

\author{
Wim H. J. Meeus \\ Utrecht University and Tilburg University
}

\begin{abstract}
A central assumption of identity theory is that adolescents reconsider current identity commitments and explore identity alternatives before they make new commitments in various identity domains (Erikson, 1968; Marcia, 1966). Yet, little empirical evidence is available on how commitment and exploration dynamics of identity formation affect each other across adolescence at the within-person level. Therefore, the current study $\left(N=494, M_{\text {age }}\right.$ Time $1=13.3$ years) examined reciprocal within-person longitudinal linkages between adolescents' identity exploration and identity commitment making in the interpersonal and educational identity domains. For this purpose, we constructed a multilevel type cross-lagged panel model from early to late adolescence (i.e., across 5 successive years). Results supported Erikson's (1968) hypothesis that adolescents reconsider current identity commitments and explore alternatives before they make strong commitments within the interpersonal identity domain across early to late adolescence. Within the educational identity domain, increasing identity commitment level and commitment fluctuations predicted less identity reconsideration over time. Our findings support identity theory, but indicate that the processes of identity formation might differ depending on the identity domain.
\end{abstract}

Keywords: identity formation, adolescence, certainty-uncertainty dynamics, longitudinal, daily diary

The formation of a clear identity is a key developmental task in adolescence (Erikson, 1968). Adolescents start searching for selfdefined values, norms and commitments and are increasingly questioning their identifications with parental values (Erikson, 1968). But is this questioning and being uncertain about current identity commitments a necessary condition for adolescents to make new personally defined and certain identity commitments over time? A central assumption of identity theory is that adoles-

Andrik I. Becht, Stefanie A. Nelemans, and Susan J. T. Branje, Research Centre Adolescent Development, Utrecht University; Wilma A. M. Vollebergh, Department of Interdisciplinary Social Sciences, Utrecht University; Hans M. Koot, Department of Developmental Psychology, VU University Amsterdam; Mental Health Program, EMGO Institute for Health and Care Research; Wim H. J. Meeus, Research Centre Adolescent Development, Utrecht University; Department of Developmental Psychology, Tilburg University.

Data of the Research on Adolescent Development and Relationships (RADAR) study were used. RADAR has been financially supported by main grants from the Netherlands Organisation for Scientific Research (GB-MAGW 480-03-005), and Stichting Achmea Slachtoffer en Samenleving (SASS) to RADAR PIs, and from the Netherlands Organisation for Scientific Research to the Consortium Individual Development (CID; 024.001.003).

Correspondence concerning this article should be addressed to Andrik I. Becht, Research Centre Adolescent Development, Utrecht University, P. O. Box 80 140, 3508 TC Utrecht, The Netherlands. E-mail: a.i.becht@ uu.nl cents reconsider current identity commitments and explore identity alternatives before they make strong commitments in various identity domains (Erikson, 1968; Marcia, 1966). Adopting the identity status paradigm (Marcia, 1966), some studies have indeed found that adolescents show progressive identity status change from identity uncertainty toward a more stable and certain identity (Kroger, Martinussen, \& Marcia, 2010; Meeus, van de Schoot, Keijsers, Schwartz, \& Branje, 2010). However, little is known about how different aspects of identity uncertainty (reconsidering current identity commitments and fluctuations in the strength of commitments) and identity commitment formation are affecting each other at the within-person level from early to late adolescence. Following the identity status paradigm to study identity formation, the aim of the current study was to test theoretical assumptions concerning longitudinal linkages between certainty and uncertainty dynamics of identity formation at the withinperson level in two salient identity domains (i.e., interpersonal and educational identity) across adolescence.

\section{Certainty and Uncertainty Dynamics Across Adolescence: Direction of Effects}

Adolescents are assumed to enter adolescence with a set of commitments in salient ideological and interpersonal identity domains that are often based on parental or peer values and norms (Crocetti, Rubini, \& Meeus, 2008). The assumption that adolescents do not start the identity formation process with a "blank slate" (Meeus, 2011; Meeus et al., 2010) is supported by findings that early adolescents already possess certain identity commit- 
ments (Archer, 1982; Meeus et al., 1999). In adolescence, these commitments are however challenged and adolescents' identity formation is considered to unfold in a dynamic of identity synthesis (or identity certainty) versus role confusion (or identity uncertainty; Erikson, 1968). In the more recent Meeus-Crocetti model, these aspects of identity formation are captured within two dimensions, commitment and reconsideration of commitment, in which adolescents form identity commitments through a process of choosing commitments and reconsidering them (Crocetti et al., 2008; Meeus et al., 2010).

One of the key assumptions of identity theory is that the process of reconsidering identity commitments and exploring identity alternatives (i.e., identity uncertainty) precedes the formation of strong and personally defined commitments (i.e., identity certainty, see Meeus, 2011 for an overview). That is, adolescents who have explored their identity commitments increasingly identify and become confident about these identity choices over time (Grotevant, 1987). This assumption regarding developmental order is reflected in three theoretical rationales.

First, adolescents typically experience an identity crisis or high levels of identity uncertainty before they start exploring and forming actual commitments (Erikson, 1968; Waterman, 1982). Also, so called moratorium-achievement-moratorium-achievement cycles (Stephen, Fraser, \& Marcia, 1992) of identity formation hypothesize that identity uncertainty, that is, exploring alternative commitments, typically will be the first step toward the reformation of a stable sense of identity. Although empirical studies directly investigating the developmental order in identity formation are scarce, progressive developmental shifts in identity statuses, as hypothesized by Waterman (1982), have been found in adolescence. That is, adolescents were more likely to change from an identity status characterized by higher identity uncertainty (i.e., moratorium status) toward identity statuses characterized by higher levels of identity certainty, such as an identity achievement status or the closure status, than vice versa (Kroger et al., 2010; Meeus et al., 2010). Likewise, college students who experienced a moratorium-like identity phase in their life (i.e., because they were in a reorientation phase of their study) showed that higher initial levels of exploring identity alternatives predicted increasing strengths in identity commitments relative to their peers, but not vice versa (Luyckx, Goossens, \& Soenens, 2006).

The second theoretical rationale suggesting developmental order is found in the conceptualization of moratorium. Moratorium, which is a state of exploring identity possibilities without having made strong commitments, is conceptualized as a status with very low stability over time, because being in a state of uncertainty is unpleasant and associated with identity distress (Waterman, 1982). Because adolescents in moratorium experience identity distress, it is unlikely that they continue to stay in this discomforting position for a prolonged period of time. In other words, identity crisis is conceptualized as something adolescents want to grow out by establishing firm commitments. Consistent with this hypothesis, stability of the moratorium status indeed appeared to be lower than that of the achievement statuses during adolescence (Kroger et al., 2010; Meeus et al., 2010).

The third theoretical rationale implying developmental order is that identity achievement is conceptualized as the final stage on an identity status continuum of identity formation, with strong commitments following after a period of identity exploration (Marcia,
1967). Empirically, the high commitment statuses (such as the identity achievement status) are indeed more likely than others to serve as endpoints of identity formation in adolescence (Meeus et al., 2010). Moreover, adolescents in the achievement identity status are the most likely to keep their strong commitments and lower levels of exploring identity alternatives compared with other identity statuses (Kroger et al., 2010).

Hence, according to identity theory and limited empirical studies, increasing commitment making might result from a period of exploration. However, it is important to look at the timing of these identity formation processes as well, because identity reconsideration and commitment making might be differentially associated depending on the time interval. For example, focusing on close time intervals, early adolescents who reported more reconsideration of identity commitments (i.e., uncertainty) at a certain day, reported less commitment making (i.e., certainty) 1 day later, relative to their peers. Similarly, adolescents who displayed more daily identity fluctuations, showed on average lower levels of identity commitments over time, compared to their peers (Klimstra et al., 2010). These findings suggest that within close time intervals adolescents' reconsideration of identity commitments is negatively related to their commitment making. However, after some time, it can be expected that reconsideration of identity commitments and identity fluctuations are followed by increasing commitment making. That is, when adolescents have had enough time to consider and reconsider identity alternatives and make firm identity commitments (Stephen et al., 1992; Waterman, 1982).

Identity fluctuations might be important to consider as well when studying identity formation processes across a longer period of time. Two suggestions have been reported why increasing identity fluctuations might predict increasing certainty in identity over time. First, developmental changes in identity have been thought to be marked by a temporal increase in fluctuations in identity (Lichtwarck-Aschoff, Van Geert, Bosma, \& Kunnen, 2008; Van Geert \& Van Dijk, 2002), followed by increasing stability or identity maturation over time. Second, fluctuations in identity commitments could be part of adolescents' evaluative process of current identity commitments which strengthens their commitments over time (Luyckx, Goossens, \& Soenens, 2006). To tap into these different processes of identity formation across a substantial amount of time, the current study investigated both reconsideration levels and commitment fluctuations as aspects of identity uncertainty in relation to commitment levels or identity certainty from early to late adolescence.

\section{Identity Formation at the Within-Person Level Across Two Identity Domains}

Especially because identity formation has been considered a highly idiosyncratic process we need to study identity formation processes at the within-person level (Lichtwarck-Aschoff et al., 2008). When investigating identity formation processes at the within-person level, it can be examined whether change occurs compared to one's own behavior instead of relative change compared with other adolescents. At the within-person level, it can be argued that when adolescents have experienced a period of increasing reconsideration of their current identity commitments, at some time, they might leave this uncertainty behind and make strong commitments to relevant ideological and interpersonal do- 
mains over time. In contrast, when studying this identity formation process at the between-person level it can be expected that adolescents with higher levels of reconsideration relative to their peers have on average lower levels of commitments compared to their peers as well. Indeed, effects at the between-person level are unrelated to within-person effects (Hamaker et al., 2015) and group-based estimates are often uninformative when considering associations between variables at the within-person level (Molenaar \& Campbell, 2009). Thus, though it may be true that, on average, adolescents with increasing reconsideration are likely to have weaker commitments over time (i.e., at the between-person level), this does not mean that when an adolescent reconsiders more, his or her commitments will become weaker over time (i.e., at the within-person level). Therefore, to uncover how changes in certainty and uncertainty dynamics of identity formation are longitudinally linked within the same individuals, the current study will apply a within-person modeling approach.

Developmental processes of identity formation may also differ across different identity domains (Meeus, Iedema, Helsen, \& Vollebergh, 1999). Consistent with Erikson's notion (1968) to study identity formation within domains that are relevant during a particular chronological period, we investigated identity formation within the school and interpersonal identity domain. Concerning the interpersonal identity domain, we considered the relationship with the best friend. That is, because the relationship with the best friend is of central importance (Laursen, 1996), and becomes increasingly important during adolescence (Helsen, Vollebergh, \& Meeus, 2000). We assessed adolescents' identity commitments and reconsideration as the extent to which adolescents feel committed to, and derive self-certainty and confidence in the future from their relationships with the best friend and their commitments to school. More recently, empirical research combining a narrative and questionnaire approach to study identity, showed that both the ideological (school) and interpersonal (i.e., friends) identity were indeed salient content domains of adolescents identity (McLean, Yoder, Syed, \& Greenhoot, 2014).

Moreover, the extent to which adolescents explore identity alternatives might depend on whether identity formation occurs in open versus more closed identity domains. Adolescents' interpersonal identity has been suggested to be more open to identity change across adolescence compared with the educational identity which becomes more closed after age 14 to 15 years. That is, within the Netherlands (the country where the present study was conducted) there are different levels of secondary education, namely, vocational education, higher professional education and university preparatory education. Within these educational levels, students have to choose a specific curricular profile around age 14 to 15 years. In addition, it is quite common to change from one school level to another school level or to change schools. Therefore, it is very plausible that early adolescents might question their educational identity. However, over time the educational identity domain becomes more closed when adolescents are following a specific educational track in which there are a limited number of alternatives available. Hence, adolescents may not find it useful to explore alternative commitments in an identity domain where they have relatively little choices (Meeus, Iedema, Helsen, \& Vollebergh, 1999). Therefore, when adolescents show increasing reconsideration in their commitment to their education this might be less strongly related to actual changes in their educational commitment making. In contrast, within the interpersonal identity domain adolescent friendships are much more open to change (Branje, Frijns, Finkenauer, Engels, \& Meeus, 2007). Accordingly, it can be hypothesized that when adolescents start reconsidering their identity commitments to a certain best friend this period of uncertainty is followed by actual changes in commitments over time. Acknowledging that identity formation processes might differ across different identity domains (Goossens, 2001; Meeus et al., 1999), the current study extends previous research by testing the validity of the hypothesized developmental sequence in identity formation at the within-person level within the interpersonal and educational identity domains (Luyckx, Goossens, Soenens, \& Beyers, 2006; Meeus, 2011).

\section{The Present Study}

This study tested a key assumption of identity theory concerning the developmental order between adolescents' uncertainty about their current identity commitments and commitment making in the process of identity formation. Although tentative predictions concerning the developmental order in certainty and uncertainty can be based on research on identity status transitions, it remains unclear how the underlying dynamics between certainty and uncertainty dimensions of the identity formation process affect each other over time within the same adolescents. Hence, our main aim was to test reciprocal within-person longitudinal linkages between adolescents' reconsideration of identity commitments, fluctuations in commitment and identity commitment levels within the interpersonal and educational identity domains. To this end, we applied a multilevel type cross-lagged panel model (see Hamaker et al., 2015) from early to late adolescence (i.e., across 5 successive years). Because identity fluctuations can be validly tapped within short-time intervals, we use daily diary reports to assess identity. Based on identity theory (Erikson, 1968), we predicted that identity uncertainty (i.e., reconsideration of commitments and commitment fluctuations) precede increasing identity commitment levels across adolescence at the within-person level. We further investigated whether this hypothesized developmental sequence applied to both the interpersonal and educational identity domains. We expected that identity uncertainty predicted identity commitment levels more strongly within the more open to change interpersonal identity domain compared to the more closed educational identity domain. Furthermore, we investigated in both identity domains whether certainty and uncertainty aspects of identity formation affect each other equally in strength from early to late adolescence. Because identity commitments of early adolescents might be less strongly internalized, socially supported and implemented (Kroger et al., 2010), we predicted that identity uncertainty more strongly predicted increasing identity commitments in early adolescence compared to late adolescence.

\section{Method}

\section{Participants}

Participants were 494 Dutch adolescents (57\% boys, $M_{\text {age }}$ Time $1=13.31, S D=0.45$ ), who enrolled in the ongoing longitudinal project Research on Adolescent Development and Relationships Young cohort (RADAR-Y). Most adolescents indicated that they 
were living with both their parents $(84.8 \%)$. Some adolescents lived with their mother $(8.3 \%)$, or elsewhere (e.g., with their father or with one biological parent and one stepparent). On the basis of parents' job level, most adolescents came from medium to high SES families $(87.9 \%)$.

Missing value analyses revealed that across five years, $86 \%$ of the possible data points were completed by the adolescents. Little's MCAR test (1988) indicated a normed chi-square $\left(\chi^{2} / d f\right)$ of 1.71 across the interpersonal and educational identity domains, indicating that it is unlikely that our findings were biased as a result of missing values. Therefore, missing data were handled in Mplus 7.31 using full information maximum likelihood.

\section{Procedure}

The current study used data from the first five waves of RADAR-Y, ages 13 to 18 . Adolescents participated in 15 measurement weeks ( 3 online assessment weeks in each of the 5 years, separated by a 3-month interval). Each measurement week, participants filled out an online questionnaire tapping into their identity formation for 5 days in a row (i.e., Monday through Friday), resulting in 75 assessments of identity. The initial Internet assessment week (T1) took place in June, the second assessment (T2) took place 3 months later in September and T3 took place in December, thus having 3-month intervals in between each assessment week. The first assessment week of the second year (i.e., T4) took place again in June, resulting in a 6-month interval between T3 (December) and T4 (June). This same assessment interval was used across 5 years. To complete the online assessments, participants had to $\log$ on to a website where they could fill out the Internet assessment. During each Internet assessment week, adolescents were reminded of participation by sending an e-mail invitation around 5:30 p.m. If adolescents did not complete the assessment $1.5 \mathrm{hr}$ after the first email invitation, they received an additional reminder email. If adolescents still had not completed the Internet assessment, they received text messages and phone calls after additional 1.5 hours. Adolescents received $€ 10$ (equivalent to US\$11) for participation for each assessment week. Participants were recruited from central and western parts of the Netherlands and all signed an informed consent form. The medical ethical committee of the University Medical Center Utrecht has approved the RADAR-study.

\section{Measures}

Adolescent identity. Adolescents reported on their identity on a daily basis across 15 measurement weeks using the single-item version of the Utrecht-Management of Identity Commitments Scale (U-MICS; Klimstra et al., 2010). The item for identity commitment was "Today, I felt confident about myself because of my best friend/school" (interpersonal and educational identity) and for reconsideration of identity, "Today, I felt that I could better look for a different best friend/school" (interpersonal and educational domain). Items were rated on a 5-point Likert scale $(1=$ completely untrue, $5=$ completely true). Validity of the singleitem questions of the U-MICS has been supported. For example, based on adolescents' scores on the single-item questions of identity commitment and reconsideration it was possible to reliable classify adolescents in theoretically meaningful identity classes
(Becht et al., 2016). Also, individual differences on these singleitem identity commitment and reconsideration questions have been related to anxiety (Becht et al., 2016; Schwartz et al., 2011), depression (Schwartz et al., 2011), aggression (Becht et al., 2016), academic adjustment (positively correlated to educational identity commitments), and supportive relationships with best-friends (positively correlated to interpersonal identity commitments, Klimstra et al., 2010). In addition, there is ample empirical evidence that the full U-MICS questionnaire measures adolescents' identity. For instance, the factor structure has been supported across different samples in different countries (Crocetti et al., 2015). Moreover, the U-MICS scores have been found to be meaningfully related to other identity measures, such as the Ego Identity Process Questionnaire-Short Form (Zimmermann, Mahaim, Mantzouranis, Genoud, \& Crocetti, 2012). Confirmatory factor analyses on the full U-MICS questionnaire (Crocetti et al., 2008) revealed that the commitment questions, "My best-friend/ school gives me certainty in life" (interpersonal and school commitment, respectively), had high factor loadings (i.e., between .90 and .95 across four waves) on the interpersonal and educational identity commitment factor. Similarly, the reconsideration of identity commitment questions, "In fact, I am looking for a best friend/different school" (interpersonal and school reconsideration, respectively), had high factor loadings (i.e., between .87 and .96 across four waves) on the interpersonal and educational reconsideration of identity commitment latent factor. Hence, these findings point out that the slightly adapted single-items of the U-MICS are important indicators of the full identity commitment and reconsideration dimensions. In addition to the validity of the single-item identity questions, these items have good reliability (Becht et al., 2016; Klimstra et al., 2010) and show longitudinal measurement invariance across adolescence (Becht et al., 2016).

For the analyses, we constructed a mean of the three assessment weeks per year, resulting in a yearly mean level score for commitment and reconsideration for interpersonal and educational identity. Additionally, we computed for each week a commitment fluctuation score based on individuals' within-person standard deviation (Ferguson, Nguyen, \& Iturbide, 2017; Kernis, Granneman, \& Barclay, 1989; Klimstra et al., 2010). Next, we calculated an average fluctuation score based on the 3 assessment weeks within each year, resulting in a yearly fluctuation score for each adolescent. Hence, there were five yearly mean level commitment and reconsideration scores and five yearly commitment fluctuations scores for the interpersonal and educational identity domains, separately.

\section{Statistical Analyses}

To answer our research question concerning longitudinal within-person linkages between certainty and uncertainty dynamics of identity formation, we constructed a random intercept crosslagged panel model (Hamaker et al., 2015) for interpersonal and educational identity, separately. This multilevel modeling approach is different from regular cross-lagged panel modeling by including a random-intercept for each construct (i.e., commitment level, commitment fluctuations, and reconsideration level) to capture stable individual differences between adolescents. That is, for each identity construct, the individual has an expected score, which is based on the sample mean across five years and the 
individual stable trait factor (i.e., the random intercept). Therefore, the variance at the within-person level captures adolescents' yearto-year fluctuations relative to their own expected score. Thus, by separating stable individual differences in identity formation processes between adolescents from within-person processes, it is possible to investigate how within-person changes in identity commitment and reconsideration are associated over time.

The interpretation of parameters in a random intercept crosslagged panel model is different than in a regular cross-lagged panel model. Most importantly, the cross-lagged parameter reflects whether an adolescent's deviation from his or her expected score can be predicted by the adolescent's deviation from his or her own score on the previous wave (Hamaker et al., 2015; Keijsers, 2016). To investigate the direction of effects between identity dimensions, we tested a fully constrained baseline model, in which all parameters were constrained to be equal across time. Specifically, we included $\mathrm{T}_{1}$ correlations, 1-year stability paths, and correlated change across $T_{2-5}$ among all constructs. Most important to our study aims, we included 1-year cross-lagged effects with commitment level predicting commitment fluctuations and reconsideration level 1 year later, commitment fluctuations predicting commitment level and reconsideration level 1 year later and reconsideration level predicting commitment level and commitment fluctuations one year later, as well as all possible reverse paths. Absolute model fit of the baseline model was evaluated using the comparative fit index (CFI), the root mean squared error of estimation (RMSEA) and the standardized root mean residual (SRMR). Fit of the baseline model was considered sufficient with CFI $>$.90, RMSEA $<.08$, and SRMR $<.08$. Our modeling approach allowed us to investigate between-person correlations between certainty and uncertainty dynamics as well, which will be reported after the results of the within-person longitudinal linkages between certainty and uncertainty dynamics.

As part of our research question, we also investigated whether changes occur in the strength of associations between certainty and uncertainty in identity formation over time. To this end, we compared our baseline model to models in which all paths of interest (i.e., cross-lagged paths) were freely estimated over time. For these model comparisons, we used the Satorra-Bentler $\chi^{2}\left(\mathrm{~S}-\mathrm{B} \chi^{2}\right)$ difference test, because we estimated our models using the maximum likelihood estimation with robust standard errors (i.e., MLR) to account for non-normal distributions (Muthén \& Muthén, 19982012).

\section{Results}

Means and standard deviations of all the study variables are displayed in Table 1.

\section{Certainty and Uncertainty Dynamics: Direction of Effects}

Interpersonal identity. Fit of the fully constrained model was good for the interpersonal identity domain, $\mathrm{S}-\mathrm{B} \chi^{2}(84)=89.62$, $\mathrm{CFI}=1.00$, RMSEA $=0.01$, and SRMR $=0.05$. Freeing the cross-lagged effects over time in a stepwise procedure for each cross-lagged effect separately, did not significantly improve model fit, $\Delta \mathrm{S}-\mathrm{B} \chi^{2}(3)$ ranging between 0.34 and 4.76 , all $p s>.190$. Therefore, we kept the most parsimonious model with all parameters constrained to be time invariant. Thereby, these findings do not support our hypothesis that experiencing identity uncertainty more strongly predicts identity commitments in early adolescence compared to later adolescence. The final model, including 1-year stability paths, concurrent associations, and cross-lagged effects can be found in Figure 1.

Consistent with our hypothesis, results indicated that adolescents' increasing reconsideration level predicted their increasing commitment level one year later. Thus, adolescents who had higher reconsideration than before in one year had higher commitments one year later. No other significant cross-paths were identified.

Other paths that were not directly answering our research question included within-person stability paths, concurrent associations and between-person correlations. Within-person stability paths indicated that commitment level was most stable, followed by reconsideration level and commitment fluctuations. As can be expected, within-person stability paths of identity fluctuations were low. Still, there was some within-person carryover effect such that years in which adolescents scored above their own expected scores were likely to be followed by years on which they scored above their expected scores as well (Hamaker et al., 2015). In addition, concurrent associations indicated that within-person deviations in commitment level were not significantly linked to within-person deviations in commitment fluctuations. However, within-person deviations in commitment level were negatively related to within-person deviations in reconsideration level, which suggests that when adolescents reported higher commitment levels

Table 1

Means and Standard Deviations (in Parentheses) for Commitment Level, Commitment

Fluctuations, and Reconsideration Level for Interpersonal and Educational Identity Across Five Waves (T1 Through T5)

\begin{tabular}{|c|c|c|c|c|c|}
\hline & $\mathrm{T} 1$ & $\mathrm{~T} 2$ & $\mathrm{~T} 3$ & $\mathrm{~T} 4$ & T5 \\
\hline Variable & $M(S D)$ & $M(S D)$ & $M(S D)$ & $M(S D)$ & $M(S D)$ \\
\hline \multicolumn{6}{|l|}{ Interpersonal identity } \\
\hline Commitment level & $2.87(.87)$ & $2.84(.90)$ & $2.86(.89)$ & $2.87(.89)$ & $2.83(.87)$ \\
\hline Commitment fluctuations & $.53(.33)$ & $.47(.32)$ & $.45(.32)$ & $.40(.30)$ & $.37(.31)$ \\
\hline Reconsideration level & $1.66(.83)$ & $1.78(.85)$ & $1.77(.88)$ & $1.83(.86)$ & $1.94(.95)$ \\
\hline \multicolumn{6}{|l|}{ Educational identity } \\
\hline Commitment level & $3.08(.76)$ & $3.05(.78)$ & $3.06(.79)$ & $3.05(.78)$ & $3.15(.77)$ \\
\hline Commitment fluctuations & $.57(.32)$ & $.53(.33)$ & $.49(.32)$ & $.48(.30)$ & $.47(.37)$ \\
\hline Reconsideration level & $1.60(.66)$ & $1.81(.78)$ & $1.84(.75)$ & $1.85(.73)$ & $1.83(.72)$ \\
\hline
\end{tabular}




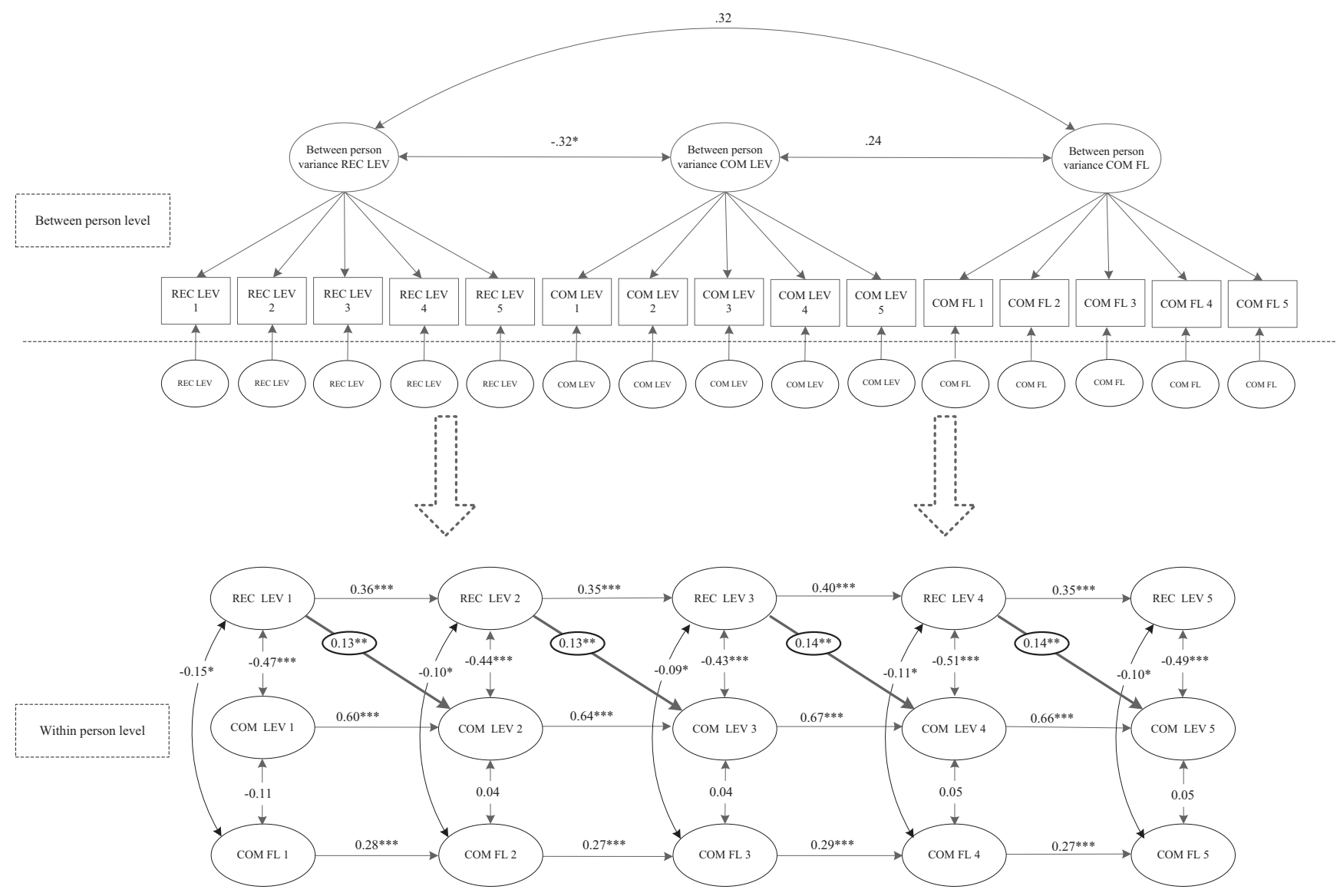

Figure 1. Graphical presentation of a within person path model with standardized associations between interpersonal reconsideration level, commitment level and commitment fluctuation. REC LEV $=$ Reconsideration level, COM LEV $=$ commitment level, COM FL $=$ commitment fluctuation. ${ }^{*} p \leq .05 .{ }^{* * *} p \leq .01 .^{* * * *} p \leq .001$.

compared to their average commitment level, they also reported lower levels of reconsideration in that same year. Moreover, within-person deviations in commitment fluctuations were negatively linked to within-person deviations in reconsideration level, suggesting that fluctuations in identity commitments might represent an ongoing evaluative identity process of current identity commitments which is related to concurrent lower levels of identity reconsideration as well.

In line with previous studies, there was a negative correlation between commitment level and reconsideration level, at the betweenperson level, indicating that adolescent who reported higher commitment levels compared to their peers, reported lower levels of reconsideration compared with their peers across 5 years (e.g., Crocetti et al., 2015).

Educational identity. Similar to the model for interpersonal identity, fit of the fully constrained model was good, $\mathrm{S}-\mathrm{B} \chi^{2}(84)=$ $123.28, \mathrm{CFI}=0.98, \mathrm{RMSEA}=0.03$, and $\mathrm{SRMR}=0.04$. Freeing the cross-lagged effects over time did not significantly improve model fit, $\Delta \mathrm{S}-\mathrm{B} \chi^{2}(3)$ ranging between 0.37 and 4.95 , all $p s>.180$. Hence, for reasons of parsimony, all cross-lagged effects could be constrained to be equal over time. Similar to the interpersonal identity domain, these findings do not support our hypothesis that experiencing identity uncertainty in the educational identity do- main more strongly predicts identity commitments in early adolescence compared to later adolescence. See Figure 2 for the final model including 1-year stability paths, concurrent associations, and cross-lagged effects.

Considering our research question regarding the direction of effects between identity uncertainty and commitments within the educational identity domain, results indicated that within-person increase in commitment level predicted less identity reconsideration one year later. Similarly, within-person increase in commitment fluctuations predicted lower levels of identity reconsideration over time. Note that within the interpersonal identity domain within-person deviations in commitment fluctuation were negatively linked to reconsideration within the same year. Within the educational identity domain this association was also negative but expressed longitudinally with commitment fluctuations predicting within-person decrease in reconsideration level one year later. Supporting our hypothesis, reconsideration level did not significantly predict commitment level within the educational identity domain.

The stability paths indicated that commitment level was relatively stable within-persons across adolescence, followed by reconsideration level and commitment fluctuations. Similar to interpersonal identity, within-person stability of educational commitment fluctuations were 


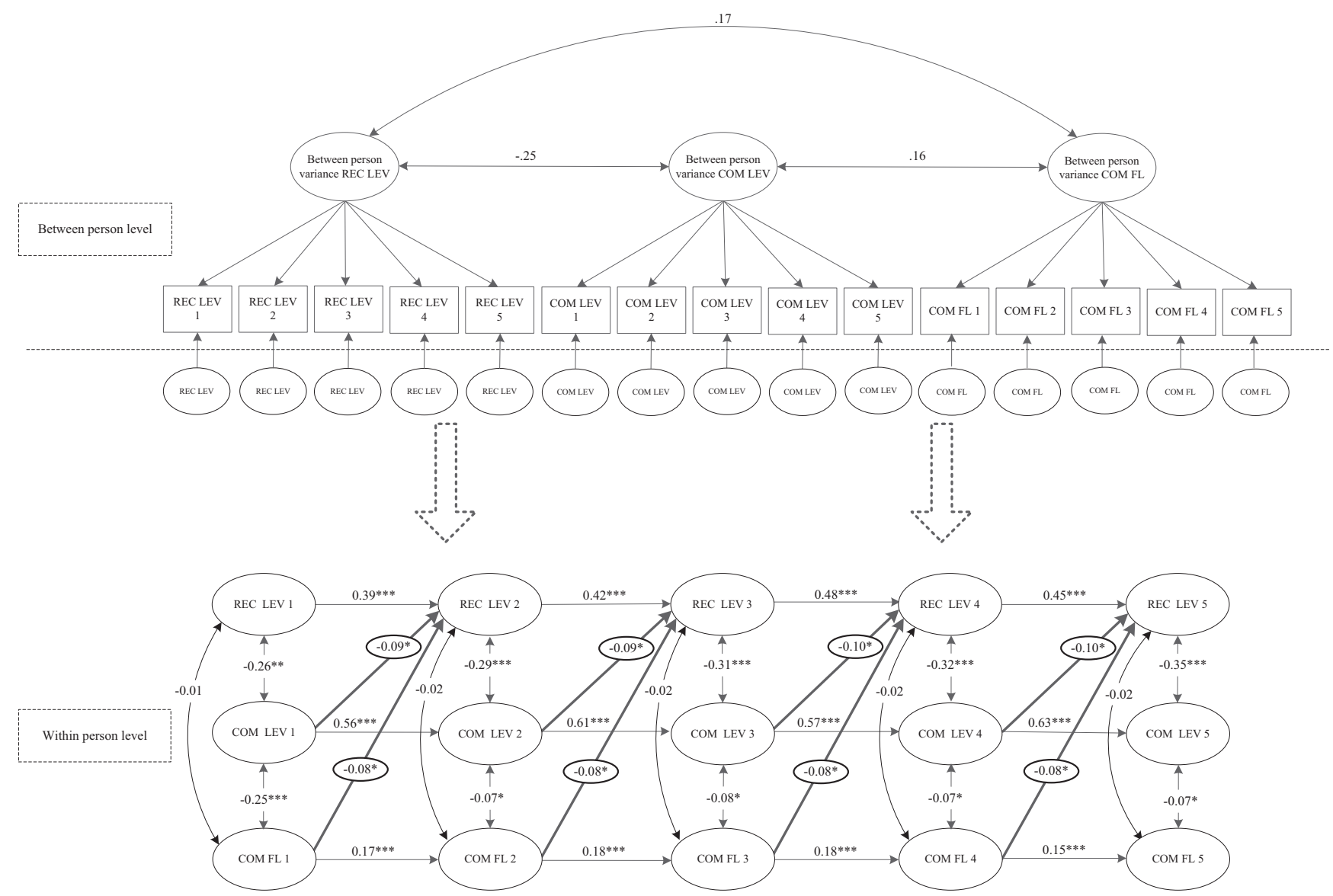

Figure 2. Graphical presentation of a within person path model with standardized associations between educational reconsideration level, commitment level and commitment fluctuation. REC LEV $=$ Reconsideration level, COM LEV $=$ commitment level, COM FL $=$ commitment fluctuation. ${ }^{*} p \leq .05 .{ }^{* * *} p \leq .01 .{ }^{* * * *} p \leq .001$.

quite low. These stability paths indicated the extent to which occasions on which adolescents scored above their own expected scores, were followed by occasions on which they scored above their expected scores as well. Moreover, concurrent associations indicated that within-person deviations in commitment level were negatively linked to within person reconsideration level and commitment fluctuations across time. Within-person deviations in reconsideration level were not linked to within-person deviations in commitment fluctuations. At the between-person level, there were no significant correlations between commitment level, commitment fluctuations, and reconsideration level.

\section{Discussion}

The present 5-year longitudinal study investigated how certainty and uncertainty aspects in the process of identity formation are related across adolescence on a within-person level. First, we found support for identity's theory's (Erikson, 1968) key assumption that adolescents increasingly reconsider current identity commitments and consider alternatives before they make strong commitments within the interpersonal identity domain. Second, within the educational identity domain we found that the certainty and uncertainty dynamics in the process of identity formation operated differently, in such a way that adolescents' increasing commitment level and commitment fluctuations predicted decreasing uncertainty of their identity commitments over time. Thus, our findings support elements of identity theory but revealed that how certainty and uncertainty aspects of identity formation affect each other differs across identity domains.

These results provide the first empirical evidence that adolescents' uncertainty in identity precedes commitment making at the within-person level from early to late adolescence for interpersonal identity (Erikson, 1968). Whereas prior longitudinal research has already found that college students' increasing consideration of identity preceded new commitment making at the between-person level (Luyckx, Goossens, \& Soenens, 2006), our findings show that this dynamic in identity formation processes also applies to the adolescent period at the within-person level. Comparing our results to a daily diary study suggests that the time interval between identity certainty and uncertainty are important to consider as well. For example, a short-term daily diary study in early adolescence found that increasing reconsideration of interpersonal identity commitments predicted decreasing commitment one day later (Klimstra et al., 2010). However, adolescents might need more than a few days or weeks to first reconsider their current identity 
commitments and explore alternative ones before they decide to change to their current commitments. Our findings indeed seem to support this idea. Specifically, higher reconsideration level of adolescents' interpersonal identity was negatively related to their commitment level within the same time-point. However, over time, increasing reconsideration level was followed by increasing commitment levels the next wave (Waterman, 1982). Alternatively, the difference between our contrasting findings compared to the Klimstra et al. (2010) study might result from taking the within-person versus the between-person perspective. That is, at the between-person level it can be suggested that adolescents who reconsider their identity commitments more compared to their peers tend to have weaker identity commitments compared with their peers (Klimstra et al., 2010). Indeed, our results confirm that at the between-person level reconsideration level and commitment level were negatively correlated (i.e., $r=-.32$ ) in our sample, similar to previous between-person studies $(r=-.32$; Crocetti et al., 2015). However, at the within-person level adolescents' increasing reconsideration was followed by increasing strengths in their commitments. In addition, our findings nicely converge with identity status research showing that adolescents are more likely to move from more uncertainty in identity profiles (e.g., moratorium) toward a more stable and certain identity (e.g., achievement; Kroger et al., 2010; Meeus et al., 2010).

The present study also extends the literature by differentiating identity formation processes in two salient identity domains, that is, the interpersonal and educational identity domains (Meeus et al., 1999). Prior research in adolescence primarily focused on identity formation in adolescents' global identity (but see, e.g., Klimstra et al., 2010 for an exception). This is unfortunate because differences have been found in developmental processes of identity formation (Goossens, 2001). In our study, we also show that the dynamic between certainty and uncertainty aspects of identity formation was different across identity domains. That is, consistent with our predictions, adolescents' uncertainty about their interpersonal identity commitments was strongest linked to commitment making regarding their interpersonal identity (Erikson, 1968). In contrast, we did not find that identity uncertainty predicted commitment making with regard to adolescents' educational identity. However, when adolescents increased in the strengths of their commitments to school, they reconsidered these identity commitments less over time. What factors might account for these differences in identity formation across different identity domains? It has been suggested that during adolescence, the interpersonal identity domain is much more open to identity change compared to the educational identity (Meeus et al., 1999). For instance, it is uncommon to choose a different school level or curricula on a regular basis in high school. Specifically, in the Netherlands students choose their school track when they are around 14 or 15 years old. Hence, the educational identity domain becomes a closed domain early on in adolescence (Meeus et al., 1999). Therefore, adolescents may not find it very useful to strongly reconsider educational alternatives. However, increasing commitments with a certain school and/or school level might help them to confirm their school choice and decrease their reconsideration of identity commitments regarding school over time. A recent study combining an identity status approach with a narrative identity approach further supported the notion that some identity domains are more open to identity change, compared with others (McLean,
Syed, \& Shucard, 2016). Moreover, results revealed the importance of examining different identity domains for a fuller understanding of identity development. Specifically, it was found that the level of identity exploration varied significantly by content domain (McLean et al., 2016). Similarly, our findings that identity uncertainty, or identity reconsideration, predicted interpersonal identity but not educational identity commitments might have resulted from differences in the meaning of the content of the friendship domain compared to the educational identity domain as a defining aspect of adolescents' identity. That is, because the interpersonal domain is more open to change during adolescence, actual exploration is an important process to find out which friends actually fit with adolescents' identity (McLean et al., 2016).

Echoing a key assumption of identity development, it has been suggested that identity maturation is marked by temporal increases in within-person variability (Lichtwarck-Aschoff et al., 2008). Consistent with this notion, an important finding of our study was that adolescents' increasing commitment fluctuations within the educational identity domain predicted less reconsideration of identity commitments over time. Our findings also confirm earlier suggestions that fluctuations in certainty about adolescents' current identity commitments reflect on ongoing evaluative process (Luyckx, Goossens, \& Soenens, 2006), which strengthens future identity commitments. Importantly, we partially replicated this finding that commitment fluctuations related to less reconsideration of commitments across the two identity domains. First, for interpersonal identity more identity fluctuations were related to less reconsideration of commitments, concurrently. Second, within the educational identity domain increasing commitment fluctuations predicted less reconsideration of commitments over time. Our results suggest that when adolescents fluctuate in the strengths of their commitments, this is not necessarily bad but instead might reflect a process of identity consolidation, evidenced by decreasing uncertainty about their commitments across adolescence. We have argued that adolescence is a key period to study identity formation processes. However, identity formation processes continue to take place during emerging adulthood. Therefore, future research should test how identity fluctuations are related to commitment making across different samples and age groups.

In contrast with our hypothesis, certainty and uncertainty dynamics were similarly affecting each other across 5 years in both interpersonal and educational identity domains, despite previous hypothesis that in early adolescence the strength of identity commitments might be more easily challenged and changed by uncertainty dynamics (Kroger et al., 2010). However, it has also been suggested that especially during college or university years uncertainty in identity commitments might temporarily increase and changes in identity formation are most prevalent compared to other age groups (Kroger et., 2010). Similarly, reflective processes on adolescents' identity have been found to increase during college years (Luyckx, Schwartz, Goossens, Soenens, \& Beyers, 2008). Future studies should investigate how certainty and uncertainty dynamics in identity formation are related at the within-person level in older age groups.

\section{Strengths, Limitations, and Future Directions}

This study is characterized by several strengths. First, our 5-year within-person longitudinal design allowed to investigate how iden- 
tity formation processes operate within the same adolescents across time, by differentiating stable trait-like between-person differences in certainty and uncertainty aspects of identity from within-person variability in identity. Second, the current study investigated identity formation from early to late adolescence which allowed to investigate identity formation processes across the whole period of adolescence. Third, we obtained a more detailed perspective on identity formation by focusing on both interpersonal and educational identity domains, as has been recommended (Goossens, 2001). Fourth, using daily measures of identity, it was possible to investigate the role and function of identity fluctuations in identity formation processes across adolescence as has been widely encouraged (e.g., Klimstra et al., 2010; Lichtwarck-Aschoff et al., 2008).

Next to these strengths, the current study also has limitations. First, the sample included mainly Dutch adolescents from relatively high socioeconomic status (SES) families. While mean level differences in identity certainty and uncertainty might differ between adolescents from different levels of family SES, future research is needed to investigate whether longitudinal associations are also different for adolescents with lower versus higher SES backgrounds. Second, although our within-person cross-lagged panel models allowed us to investigate within-person longitudinal associations in identity formation this model is not suitable for analyzing heterogeneity in these within-person processes. Therefore, the current results represent the average within-person effects across all participants in the sample but did not take into account potential heterogeneity in these within-person processes (Keijsers, 2016). Third, although we focused on two important domains of personal identity formation (i.e., interpersonal identity domain and the educational identity domain), the identity construct includes additional domains that are important to address in future studies. For example, ethnic identity is a key developmental milestone for migrant youth (Rivas-Drake et al., 2014). Therefore, future studies should include heterogeneous samples in terms of ethnicity to investigate identity formation processes across different identity domains and across different samples. Moreover, while the relationship with the best friend is of central importance during adolescence (e.g., Helsen et al., 2000), other personal identity contents become important as well during adolescence. For example, content domains such as romantic relationships, sex roles, and political values become increasingly relevant during adolescence and young adulthood (e.g., Mclean et al., 2016). Future work should therefore further investigate the identity exploration-commitment making dynamic within these content domains. Moreover, future work could benefit from combining an identity status approach with a narrative identity approach to further our understanding of the processes underlying identity formation (McLean et al., 2016). Fourth, we report one of the first empirical evidence that increasing commitment fluctuations predicted stronger educational identity commitments over time. However, a next step would be to zoom in and investigate whether short-term increasing identity fluctuations mark a transition point for adolescents' identity. For example, can the transition from secondary school to college be predicted by temporally increasing identity fluctuations?

Despite these limitations, the current study supported the view that adolescents typically experience identity uncertainty and consider identity alternatives before they make strong commitments regarding their interpersonal identity (Erikson, 1968). In contrast, increasing identity commitments and commitment fluctuations predicted adolescents' decreasing uncertainty about their educational commitments across adolescence. We investigated these longitudinal associations on a within-person level. When adolescents have increasingly reconsidered and explore identity alternatives, strong commitments are likely to follow.

\section{References}

Archer, S. (1982). The lower age boundaries of identity development. Child Development, 53, 1551-1556. http://dx.doi.org/10.2307/1130083

Balistreri, E., Busch-Rossnagel, N. A., \& Geisinger, K. F. (1995). Development and preliminary validation of the Ego Identity Process Questionnaire. Journal of Adolescence, 18, 179-192. http://dx.doi.org/10 .1006/jado.1995.1012

Becht, A. I., Branje, S. J., Vollebergh, W. A., Maciejewski, D. F., van Lier, P. A., Koot, H. M., . . . Meeus, W. H. (2016). Assessment of identity during adolescence using daily diary methods: Measurement invariance across time and sex. Psychological Assessment, 28, 660-672. http://dx .doi.org/10.1037/pas0000204

Becht, A. I., Nelemans, S. A., Branje, S. J., Vollebergh, W. A., Koot, H. M., Denissen, J. J., \& Meeus, W. H. (2016). The quest for identity in adolescence: Heterogeneity in daily identity formation and psychosocial adjustment across 5 years. Developmental Psychology, 52, 2010-2021. http://dx.doi.org/10.1037/dev0000245

Branje, S. J., Frijns, T., Finkenauer, C., Engels, R., \& Meeus, W. (2007). You are my best friend: Commitment and stability in adolescents' same-sex friendships. Personal Relationships, 14, 587-603. http://dx .doi.org/10.1111/j.1475-6811.2007.00173.x

Crocetti, E., Cieciuch, J., Gao, C. H., Klimstra, T., Lin, C. L., Matos, P. M., . . Meeus, W. (2015). National and gender measurement invariance of the Utrecht-Management of Identity Commitments Scale (U-MICS): A 10-nation study with university students. Assessment, 22, 753-768. http://dx.doi.org/10.1177/1073191115584969

Crocetti, E., Rubini, M., \& Meeus, W. (2008). Capturing the dynamics of identity formation in various ethnic groups: Development and validation of a three-dimensional model. Journal of Adolescence, 31, 207-222. http://dx.doi.org/10.1016/j.adolescence.2007.09.002

Crocetti, E., Scrignaro, M., Sica, L. S., \& Magrin, M. E. (2012). Correlates of identity configurations: Three studies with adolescent and emerging adult cohorts. Journal of Youth and Adolescence, 41, 732-748. http:// dx.doi.org/10.1007/s10964-011-9702-2

Erikson, E. (1968). Youth: Identity and crisis. New York, NY: Norton. http://dx.doi.org/10.1126/science.161.3838.257

Ferguson, G. M., Nguyen, J., \& Iturbide, M. I. (2017). Playing up and playing down cultural identity: Introducing cultural influence and cultural variability. Cultural Diversity \& Ethnic Minority Psychology, 23, 109-124. http://dx.doi.org/10.1037/cdp0000110

Goossens, L. (2001). Global versus domain-specific statuses in identity research: A comparison of two self-report measures. Journal of Adolescence, 24, 681-699. http://dx.doi.org/10.1006/jado.2001.0438

Grotevant, H. D. (1987). Toward a process model of identity formation. Journal of Adolescent Research, 2, 203-222. http://dx.doi.org/10.1177/ 074355488723003

Hamaker, E. L., Kuiper, R. M., \& Grasman, R. P. (2015). A critique of the cross-lagged panel model. Psychological Methods, 20, 102-116. http:// dx.doi.org/10.1037/a0038889

Helsen, M., Vollebergh, W., \& Meeus, W. (2000). Social support from parents and friends and emotional problems in adolescence. Journal of Youth and Adolescence, 29, 319-335. http://dx.doi.org/10.1023/a: 1005147708827

Keijsers, L. (2016). Parental monitoring and adolescent problem behaviors How much do we really know? International Journal of Behavioral 
Development, 40, 271-281. http://dx.doi.org/10.1177/01650254155 92515

Kernis, M. H., Grannemann, B. D., \& Barclay, L. C. (1989). Stability and level of self-esteem as predictors of anger arousal and hostility. Journal of Personality and Social Psychology, 56, 1013-1022. http://dx.doi.org/ 10.1037/0022-3514.56.6.1013

Klimstra, T. A., Luyckx, K., Hale, W. A., III, Frijns, T., van Lier, P. A., Meeus, W. H., \& Meeus, W. H. J. (2010). Short-term fluctuations in identity: Introducing a micro-level approach to identity formation. Journal of Personality and Social Psychology, 99, 191-202. http://dx.doi .org/10.1037/a0019584

Kroger, J., Martinussen, M., \& Marcia, J. E. (2010). Identity status change during adolescence and young adulthood: A meta-analysis. Journal of Adolescence, 33, 683-698. http://dx.doi.org/10.1016/j.adolescence.2009 .11 .002

Laursen, B. (1996). Closeness and conflict in adolescent peer relationships: Interdependence with friends and romantic partners. In W. M. Bukowski, A. F. Newcomb, \& W. W. Hartup (Eds.), The company they keep: Friendships in childhood and adolescence. New York, NY: Cambridge University Press.

Lichtwarck-Aschoff, A., van Geert, P., Bosma, H., \& Kunnen, S. (2008). Time and identity: A framework for research and theory formation. Developmental Review, 28, 370-400. http://dx.doi.org/10.1016/j.dr .2008.04.001

Luyckx, K., Goossens, L., \& Soenens, B. (2006). A developmental contextual perspective on identity construction in emerging adulthood: Change dynamics in commitment formation and commitment evaluation. Developmental Psychology, 42, 366-380. http://dx.doi.org/10 $.1037 / 0012-1649.42 .2 .366$

Luyckx, K., Goossens, L., Soenens, B., \& Beyers, W. (2006). Unpacking commitment and exploration: Preliminary validation of an integrative model of late adolescent identity formation. Journal of Adolescence, 29, 361-378. http://dx.doi.org/10.1016/j.adolescence.2005.03.008

Luyckx, K., Klimstra, T. A., Duriez, B., Van Petegem, S., Beyers, W., Teppers, E., \& Goossens, L. (2013). Personal identity processes and self-esteem: Temporal sequences in high school and college students. Journal of Research in Personality, 47, 159-170. http://dx.doi.org/10 .1016/j.jp. 2012.10.005

Luyckx, K., Schwartz, S. J., Goossens, L., Soenens, B., \& Beyers, W. (2008). Developmental typologies of identity formation and adjustment in female emerging adults: A latent class growth analysis approach. Journal of Research on Adolescence, 18, 595-619. http://dx.doi.org/10 .1111/j.1532-7795.2008.00573.x

Marcia, J. E. (1966). Development and validation of ego-identity status. Journal of Personality and Social Psychology, 3, 551-558. http://dx.doi .org/10.1037/h0023281

Marcia, J. E. (1967). Ego identity status: Relationship to change in selfesteem, "general maladjustment," and authoritarianism. Journal of Personality, 35, 118-133. http://dx.doi.org/10.1111/j.1467-6494.1967 .tb01419.x

Marcia, J. E. (1993). The ego identity status approach to ego identity. In J. E. Marcia, A. S. Waterman, D. R. Matteson, S. L. Archer, \& J. L. Orlofsky (Eds.), Ego identity. A handbook for psychosocial research (pp. 3-21). New York, NY: Springer-Verlag. http://dx.doi.org/10.1007/ 978-1-4613-8330-7_1

McLean, K. C., Syed, M., \& Shucard, H. (2016). Bringing identity content to the fore: Links to identity development processes. Emerging Adulthood, 4, 356-364. http://dx.doi.org/10.1177/2167696815626820
McLean, K. C., Syed, M., Yoder, A., \& Greenhoot, A. F. (2014). The role of domain content in understanding identity development processes. Journal of Research on Adolescence, 26, 60-75. http://dx.doi.org/10 .1111 jora. 12169

Meeus, W. (2011). The study of adolescent identity formation 2000-2010: A review of longitudinal research. Journal of Research on Adolescence, 21, 75-94. http://dx.doi.org/10.1111/j.1532-7795.2010.00716.x

Meeus, W., Iedema, J., Helsen, M., \& Vollebergh, W. (1999). Patterns of adolescent identity development: Review of literature and longitudinal analysis. Developmental Review, 19, 419-461. http://dx.doi.org/10 $.1006 /$ drev.1999.0483

Meeus, W., van de Schoot, R., Keijsers, L., Schwartz, S. J., \& Branje, S. (2010). On the progression and stability of adolescent identity formation: A five-wave longitudinal study in early-to-middle and middle-to-late adolescence. Child Development, 81, 1565-1581. http://dx.doi.org/10 $.1111 / \mathrm{j} .1467-8624.2010 .01492 . x$

Molenaar, P. C., \& Campbell, C. G. (2009). The new person-specific paradigm in psychology. Current Directions in Psychological Science, 18, 112-117. http://dx.doi.org/10.1111/j.1467-8721.2009.01619.x

Muthén, L. K., \& Muthén, B. O. (1998-2012). Mplus user's guide (7th ed.). Los Angeles, CA: Authors.

Rivas-Drake, D., Seaton, E. K., Markstrom, C., Quintana, S., Syed, M., Lee, R. M., . . . the Ethnic and Racial Identity in the 21st Century Study Group. (2014). Ethnic and racial identity in adolescence: Implications for psychosocial, academic, and health outcomes. Child Development, 85, 40-57. http://dx.doi.org/10.1111/cdev. 12200

Schwartz, S. J., Klimstra, T. A., Luyckx, K., Hale, W. W., III, Frijns, T., Oosterwegel, A., . . . Meeus, W. H. J. (2011). Daily dynamics of personal identity and self-concept clarity. European Journal of Personality, 25, 373-385. http://dx.doi.org/10.1002/per.798

Stephen, J., Fraser, E., \& Marcia, J. E. (1992). Moratorium-achievement (MAMA) cycles in lifespan identity development: Value orientations and reasoning system correlates. Journal of Adolescence, 15, 283-300. http://dx.doi.org/10.1016/0140-1971(92)90031-Y

Van Geert, P., \& Van Dijk, M. (2002). Focus on variability: New tools to study intra-individual variability in developmental data. Infant Behavior and Development, 25, 340-374. http://dx.doi.org/10.1016/S01636383(02)00140-6

Waterman, A. S. (1982). Identity development from adolescence to adulthood: An extension of theory and a review of research. Developmental Psychology, 18, 341-358. http://dx.doi.org/10.1037/0012-1649.18.3.341

Waterman, A. S. (2015). What does it mean to engage in identity exploration and to hold identity commitments? A methodological critique of multidimensional measures for the study of identity processes. Identity: An International Journal of Theory and Research, 15, 309-349. http:// dx.doi.org/10.1080/15283488.2015.1089403

Zimmermann, G., Mahaim, E. B., Mantzouranis, G., Genoud, P. A., \& Crocetti, E. (2012). Brief report: The Identity Style Inventory (ISI-3) and the Utrecht-Management of Identity Commitments Scale (U-MICS): Factor structure, reliability, and convergent validity in French-speaking university students. Journal of Adolescence, 35, 461-465. http://dx.doi .org/10.1016/j.adolescence.2010.11.013 http://dx.doi.org/10.1037/0012 1649.18.3.341

Received April 15, 2016

Revision received February 22, 2017 Accepted April 25, 2017 